\title{
Pro-shareholder income distribution, debt accumulation, and cyclical fluctuations in a post-Keynesian model with labor supply constraints*
}

\author{
Hiroaki Sasaki \\ Graduate School of Economics, Kyoto University, Japan \\ Shinya Fujita \\ Graduate School of Economics, Nagoya University, Japan
}

\begin{abstract}
In modern capitalist economies, income distribution has a tendency to be in favor of shareholders. This paper interprets pro-shareholder distribution as a decrease in the retention ratio of firms and an increase in the profit share. We introduce labor supply constraints into a post-Keynesian growth model with debt accumulation and investigate the effects of changes in the natural rate of growth, retention ratio, profit share, and interest rate on the rate of capacity utilization and the financial structure of firms. We further analyse the stability of the steady-state equilibrium and the transitional dynamics toward the equilibrium and show that, depending on conditions, there could be cyclical fluctuations such that the financial structure changes periodically between speculative finance and Ponzi finance.
\end{abstract}

Keywords: financial structure, labor supply constraints, post-Keynesian model, cyclical fluctuations

JEL codes: E12, E21, E22, E32, E44

\section{INTRODUCTION}

In the modern capitalist economies, income distribution has a tendency to be in favor of shareholders; this has arisen from an increase in the power of shareholders. For example, Stockhammer (2004) points out the increased income share of rentiers in France, Germany, the UK, and the US. Epstein/Power (2003) reveal that, in the OECD countries after the 1980s, the income share of the rentiers has been rapidly increasing and the profit share of non-financial corporations mildly increasing. Skott/Ryoo (2008) show that, in the US economy, the retention ratio of firms declined from 1970 up to 2005.

This tendency also holds true in the Japanese economy. The corporate governance of Japanese firms has turned to shareholder value orientation since the late 1990s, and the

\footnotetext{
* Early versions of this paper were presented at the 16th Conference of the Research Network Macroeconomics and Macroeconomic Policies (FMM), Berlin, 2012, and the Workshop on Analytical Political Economy in Japan, Hitotsubashi University, 2012. We would like to thank participants and two anonymous referees for their helpful comments and suggestions. Shinya Fujita is grateful to JSPS KAKENHI Grant Number 24730267 for financial support.
}

Received 24 April 2013, accepted 12 August 2013 


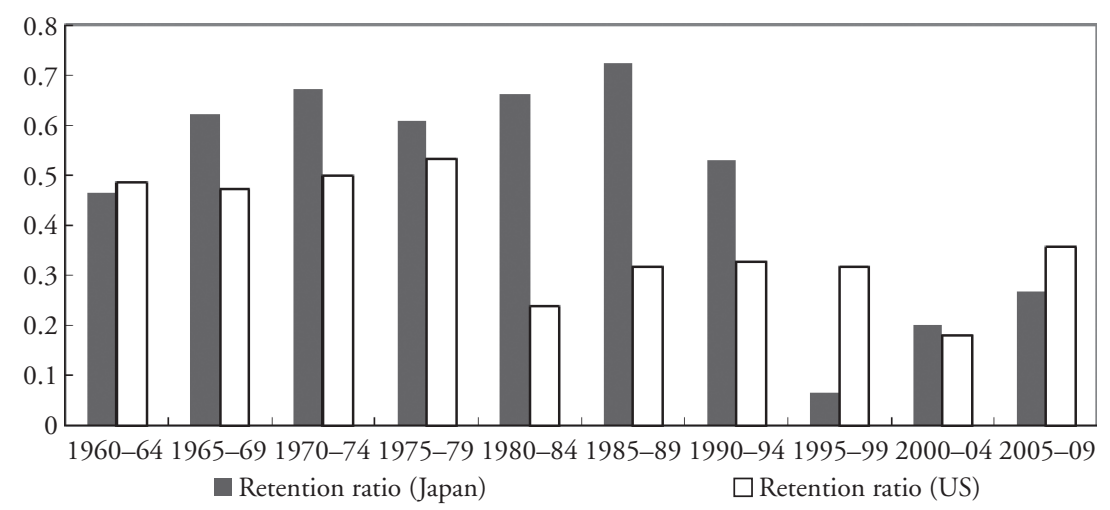

Sources: Financial Statements Statistics of Corporations by Industry, Policy Research Institute, Ministry of Finance, Japan. National Income and Product Accounts, Bureau of Economic Analysis, US Department of Commerce.

Figure 1 The retention ratio in Japan and the US (1960-2009)

propensity to distribute dividends has accordingly increased. In other words, the retention ratio of Japanese firms has decreased. ${ }^{1}$ The main reason for this is that the old custom of mutual shareholding has collapsed and the number of foreign shareholders has increased rapidly. As Figure 1 shows, the retention ratio of Japanese firms consistently exceeded 60 percent from the late 1960s through the late 1980s, although has remained consistently lower than 30 percent from the late 1990 s to the present day. ${ }^{2}$

Many empirical and theoretical studies have investigated the effect of pro-shareholder income distribution on the macro economy. ${ }^{3}$

To begin with, we turn to a few empirical studies. Stockhammer (2004), already cited above, shows that the increased income share of rentiers in France, the UK, and the US depresses the equipment investment of firms. Van Treeck (2008) shows that increases in the profit share and the income share of rentiers can lead to increased profitability by increasing the consumption demand on the one hand, but not leading to higher capital accumulation on the other. Onaran et al. (2011) analyse how financialization and the resulting changes in income distribution affect the aggregate demand in the US economy. They conclude that any change in income distribution favoring capital has a positive effect on consumption demand through a wealth effect and a negative effect on investment

1. In Hein/van Treeck (2010a) and in Hein (2012), shareholder power affects the dividend rate and thus the retention ratio. See also Hein (2010), where rising shareholder power is associated with a rising dividend rate and decreasing management animal spirits. Some researchers believe that the retention ratio is not a policy variable determined by firms but a variable determined ex post. However, some studies empirically show that firms determine their dividend payout ratio - that is, their retention ratio. See Brav et al. (2005), DeAngelo et al. (1992), Denis/Osobov (2008), and Fama/ French (2001).

2. The retention ratio is calculated by dividing the retained earnings (defined as the net profits of a term - the dividend at the term end - the remuneration of officials at the term end) by the profits (defined as the retained earnings + the dividend at the term end).

3. For the microeconomic effects of shareholder value orientation on firms' behavior, see Dallery (2009). 
demand; these two effects offset each other and consequently have a neutralizing effect on the economy's aggregate demand.

However, Stockhammer (2004) estimates the investment functions only and does not consider consumption demand. Furthermore, he performs a short-run analysis and does not consider endogenous changes in the debt-capital ratio. Van Treeck (2008) and Onaran et al. (2011) consider the effects of financialization on both consumption and investment and hence are more general than Stockhammer (2004). However, these studies too are short-run analyses and do not consider debt/capital accumulation.

Next, we turn to a few theoretical studies. Hein/van Treeck (2010a) analytically investigate the effect of increased shareholder power on the macro economy by using a Kaleckian model with two investment functions, the Kalecki-type investment function and Bhaduri/ Marglin's (1990) investment function. ${ }^{4}$ They show that various demand regimes occur in accordance with the size of parameters. Hein (2012) builds a Kaleckian model that considers the effect of a rise in shareholder power on productivity growth, and theoretically investigates its effect on the short-run capital accumulation and labor productivity growth. He concludes that, even if the productivity-enhancing effect of rising shareholder power is considered, the total effect of the power of shareholders on the macro economy is likely to be negative. These studies do not assume a constant financial structure of the firm sector. However, they do not explicitly analyse endogenous change of the financial structure.

For a long-run theoretical analysis, we can refer to Skott/Ryoo (2008). First, this study shows that the US economy experiences pro-shareholder income distribution under financialization. Then, using both a Harrodian model and a Kaleckian model (without labor supply constraints), they theoretically investigate the effect of a decrease in retention ratio of firms on the macro variables. Limiting our discussion to the Kaleckian model used in their paper, we find the effect of a decrease in the firms' retention ratio on the macro economy to be expansionary.

We investigate the effect of pro-shareholder income distribution on the macro variables by using an otherwise Kaleckian model with debt accumulation. In order to investigate pro-shareholder income distribution of a capitalist economy with near-full employment, we need to build a mature economy model in which labor supply constraints bind. When we incorporate labor supply constraint into the Kaleckian model, the model turns into a Kaldorian model in that the rate capital accumulation is equal to the natural rate of growth, and firms' animal spirits do not affect the rate of capacity utilization in the steady state. Therefore, we consider our model as Kaldorian.

To our knowledge, Ryoo/Skott (2008) is the only study using an otherwise Kaleckian model with labor supply constraints to examine the effect of income distribution on the macro economy. This study is a continuation of Skott/Ryoo (2008) and theoretically shows that the effect of a decrease in the retention ratio of firms is expansionary even in a labor-constrained economy. In the present paper, we build a similar model. However, our method and objectives are largely different from those of Ryoo/Skott (2008).

First, Ryoo/Skott (2008) use numerical calculations for their comparative static analysis. This is because their model is complicated and analytical solutions are hard to obtain. By contrast, we simplify their somewhat complicated settings and obtain our main results through comparative static analysis by using an analytical method.

4. We consider Hein/van Treeck (2010b) as a related study. They theoretically analyse whether financialization has an expansive effect or a contractive effect on the macro economy from some aspects. Using a Kaleckian model, Hein (2010) analytically investigates how increasing shareholder power affects the macro economy. He considers both the medium term, where the outside financecapital ratio changes, and the short term. 
Second, they limit their analysis to the steady-state equilibrium and hence do not consider the stability and transitional dynamics of a long-run equilibrium. By contrast, we explicitly investigate the stability and transitional dynamics of the equilibrium. According to our analysis, the steady-state equilibrium can be stable or unstable, and, depending on conditions, there can be perpetual business cycles.

Moreover, we employ the Minskyan taxonomy of financial structure of firms. That is, we investigate whether the financial structure of firms becomes hedge finance, speculative finance, or Ponzi finance (Minsky 1975; 1982).

For existing studies investigating the financial structure of firms using Kaleckian models, we consider Charles (2008a), Foley (2003), Lima/Meirelles (2007), and Nishi (2012). In these studies, the financial structure remains as speculative or Ponzi finance after the economy reaches the steady-state equilibrium. By contrast, we show that cyclical fluctuations can occur such that the financial structure of firms changes periodically between speculative finance and Ponzi finance.

The rest of the paper is organized as follows. Section 2 derives the dynamic equations of the rate of capital accumulation, debt-capital ratio, and capital-effective labor supply ratio. Section 3 obtains the steady-state equilibrium, investigates which financial regime the firms belong to, and in addition examines the stability of the steady-state equilibrium. Section 4 presents the results of comparative static analysis. Section 5, using numerical simulations, analyses how the financial structure of firms evolves along a transitional path to the steady state. Section 6 concludes the paper.

\section{MODEL}

We consider a one-sector, one-good, closed economy with no government sector. The economy has three types of agents: firms, households, and banks. Firms produce goods using capital stock and labor services supplied by households. Following the post-Keynesian horizontalist approach (Moore 1988; Rochon 1999), we assume that firms borrow their investment funds from households via the banking sector at a constant nominal lending interest rate, and engage in investments using the borrowed funds and their retained earnings. Further, they do not issue new equities for investment but issue equities at the time of starting their business. Since all these equities are held by households, households receive wage income, interest income, and dividend income (Ryoo/Skott 2008; Skott/ Ryoo 2008; Taylor 2004). Households spend a constant fraction of their total income on consumption and save the rest. Banks lend the deposits they receive from the households to the firms. However, we assume that the deposit and lending interest rates are equal and hence banks incur no costs and make no profits.

\subsection{Dynamics of the rate of capital accumulation}

The firms in the economy produce goods with a fixed coefficient production function. We assume that the potential output-capital ratio is constant. If we denote the actual output and the capital stock as $Y$ and $K$ respectively, then the rate of capacity utilization can be denoted as $u=Y / K .^{5}$ Firms' retained earnings $\Pi_{f}$ are obtained by subtracting

5. Strictly speaking, the rate of capacity utilization in this paper is the output-capital ratio. The rate of capacity utilization is decomposed into output-capital ratio and capital-potential output ratio. If we assume that the capital-potential output ratio is constant, then the rate of capacity utilization and the output-capital ratio change in the same direction. Therefore, we can regard the output-capital ratio as the rate of capacity utilization. 
the dividend and interest payments with regard to their real debt $L$ from total profits. Dividing by $K$ yields:

$$
\frac{\Pi_{f}}{K}=s_{f}\left(\pi u-i \frac{L}{K}\right)=s_{f}(\pi u-i \lambda), s_{f} \in(0,1), \pi \in(0,1), i>0,
$$

where $s_{f}$ denotes the retention ratio, $\pi$ the profit share, $i$ the nominal interest rate, and all the parameters are assumed to be constant. In addition, $\lambda=L / K$ denotes the debt-capital ratio.

The households receive wage income, interest income, and dividend income, and hence their total income $\Pi_{b}$ divided by $K$ can be obtained by:

$$
\frac{\Pi_{h}}{K}=(1-\pi) u+i \frac{L}{K}+\left(1-s_{f}\right)\left(\pi u-i \frac{L}{K}\right)=\left(1-s_{f} \pi\right) u+s_{f} i \lambda .
$$

Let a constant $s_{h}$ be the households' propensity to save. ${ }^{6}$ From Equations (1) and (2), the total real savings $S$ divided by $K$ is given by:

$$
\frac{S}{K}=s_{f}(\pi u-i \lambda)+s_{h}\left[\left(1-s_{f} \pi\right) u+s_{f} i \lambda\right], s_{h} \in(0,1) .
$$

In a short-run adjustment process, saving adjusts to given investment $g$ via a change in capacity utilization $u$, and then the short-run goods market equilibrium condition is given by $g=S / K$. From this, we obtain the following relationship between the rates of capacity utilization and capital accumulation:

$$
u=\frac{g+s_{f}\left(1-s_{h}\right) i \lambda}{s_{f} \pi\left(1-s_{h}\right)+s_{h}} .
$$

We assume that the firms' target capital accumulation rate $g^{d}$ is an increasing function of the retained earnings per capital stock and of the capacity utilization rate (Hein 2006; Kalecki 1954) and a decreasing function of the employment rate $e$ :

$$
g^{d}=\alpha+\beta s_{f}(\pi u-i \lambda)+\gamma u-\delta e, \alpha>0, \beta>0, \gamma \geq 0, \delta>0
$$

Many empirical studies show that the equipment investment of firms depends positively on the current retained earnings (Fazzari et al. 1988; Hayashi/Inoue 1991; Hoshi et al. 1991; Ndikumana 1999). ${ }^{7}$

In addition, we introduce the effect of the employment rate on the target capital accumulation rate in order to consider the role of the employment rate in a mature economy. The usual method of endogenously determining the employment rate is to introduce the negative effect of the employment rate - that is, the reserve army effect - on the profit share (Cassetti 2003; Dutt 1992; Flaschel/Skott 2006; Sasaki 2013). However, if we adopt this method, we have to add a dynamic equation of the profit share to our dynamic model and conduct more complicated calculations. Thus, introducing the employment rate into the investment function is the simplest way to endogenize the employment

6. Our saving function is similar to that of Kaldor (1966) in that firms and households save their profits, and is different from that of Kaleckians such as Hein $(2006 ; 2007)$ and Charles $(2008 \mathrm{a}$; 2008b) who assume that workers do not save and only firms and capitalists save.

7. In a theoretical study, Charles (2008a; 2008b) assumes an investment function with $\gamma=0$ and $\delta=0$. 
rate (Ryoo/Skott 2008; Skott/Zipperer 2012). In this paper, we consider a negative effect of the employment rate on investment.

The negative effect of the employment rate on investment is justified by the following two factors. First, if the economy is near full employment, the firms' opportunity to employ more workers and expand production will be lost, just as will their incentive to accumulate capital stock. Remember that, in our model, labor supply constraints bind. Second, as the economy approaches full employment, the bargaining power of the workers would increase, which in turn raises the real wage rate via the reserve army effect. An increase in the real wage rate squeezes the profit of firms and reduces investment. These possibilities are given by Ryoo/Skott (2008) and Skott/Zipperer (2012).

However, we must note that the second justification has a shortcoming. When the employment rate increases and, accordingly, the real wage increases, the profit share necessarily decreases as long as labor productivity is constant, which contradicts the assumption of a constant profit share in our model. Therefore, in the following analysis, we proceed with the first justification.

Next, if we denote employment as $E$, the level of labor productivity as $A=Y / E$, and labor supply as $N$, the employment rate can be shown as:

$$
e=\frac{E}{N}=\frac{Y}{K} \cdot \frac{K}{A N}=u \widetilde{k}
$$

where $\widetilde{k}=K /(A N)$ denotes the capital-effective labor supply ratio. Substituting Equation (6) into Equation (5), we obtain:

$$
g^{d}=\alpha+\beta s_{f}(\pi u-i \lambda)+(\gamma-\delta \widetilde{k}) u .
$$

We assume that the actual capital accumulation rate is adjusted according to the difference between the target and actual capital accumulation rates (Skott/Zipperer 2012):

$$
\dot{g}=\phi\left(g^{d}-g\right), \phi>0,
$$

where the dot over a variable denotes the time derivative of the variable and $\phi$ the speed of adjustment. Substituting Equations (4) and (5') into Equation (7), we obtain:

$\dot{g}=g(g, \lambda, \widetilde{k}) \equiv \phi\left\{-\frac{s_{f} \pi\left(1-s_{h}-\beta\right)+s_{h}-\gamma+\delta \widetilde{k}}{s_{f} \pi\left(1-s_{h}\right)+s_{h}} g+\frac{\left[(\gamma-\delta \widetilde{k})\left(1-s_{h}\right)-\beta s_{h}\right]}{s_{f} \pi\left(1-s_{h}\right)+s_{h}} s_{f} i \lambda+\alpha\right\}$.

\subsection{Dynamics of the debt-capital ratio}

Log-differentiating the debt-capital ratio, we obtain:

$$
\dot{\lambda}=\left(\frac{\dot{L}}{L}-\frac{\dot{K}}{K}\right) \lambda=\frac{\dot{L}}{K}-g \lambda .
$$

The increment of debt is equal to the actual investment less the retained earnings. Therefore, from Equation (4), the increment of debt per capital can be shown as follows:

$$
\frac{\dot{L}}{K}=g-s_{f}(\pi u-i \lambda)=\frac{s_{h}\left(1-s_{f} \pi\right)}{s_{f} \pi\left(1-s_{h}\right)+s_{h}} g+\frac{s_{f} s_{h}}{s_{f} \pi\left(1-s_{h}\right)+s_{h}} i \lambda
$$


Substituting Equation (10) into Equation (9), we obtain the dynamic equation of the debt-capital ratio:

$$
\dot{\lambda}=\lambda(g, \lambda) \equiv \frac{s_{h}\left(1-s_{f} \pi\right)-\left[s_{f} \pi\left(1-s_{h}\right)+s_{h}\right] \lambda}{s_{f} \pi\left(1-s_{h}\right)+s_{h}} g+\frac{s_{f} s_{h}}{s_{f} \pi\left(1-s_{b}\right)+s_{h}} i \lambda .
$$

\subsection{Dynamics of the capital-effective labor supply ratio}

We assume that the productivity of labor and the supply of labor grow at constant rates $n_{1}$ and $n_{2}$, respectively. ${ }^{8}$ Log differentiating the capital-effective labor supply ratio, we obtain the dynamic equation of $\widetilde{k}$ as follows:

$$
\dot{\tilde{k}}=\widetilde{k}(g) \equiv(g-n) \widetilde{k}, n>0,
$$

where $n \equiv n_{1}+n_{2}$, which we call the 'natural rate of growth.'

\section{PROPERTIES OF THE STEADY-STATE EQUILIBRIUM}

\subsection{Steady-state values}

From the above analysis, we have a dynamic system composed of Equations (8), (11), and (12). The steady-state equilibrium of the system is a situation in which $\dot{g}=\dot{\lambda}=\dot{\widetilde{k}}=0$. Let the steady-state values be denoted as $g^{*}, \lambda^{*}$, and $\widetilde{k}^{*}$.

To begin with, Equation (12) indicates that the steady-state value of the capital accumulation rate is equal to the natural growth rate: ${ }^{9}$

$$
g^{*}=n
$$

Next, substituting Equation (13) into Equation (11), we obtain the steady-state value of the debt-capital ratio as follows:

$$
\lambda^{*}=\frac{s_{h} n\left(1-s_{f} \pi\right)}{\left[s_{f} \pi\left(1-s_{h}\right)+s_{h}\right] n-s_{f} s_{h} i}=\frac{s_{h} n\left(1-s_{f} \pi\right)}{s_{h} n\left(1-s_{f} \pi\right)+s_{f}\left(\pi n-s_{h} i\right)} .
$$

Note that $\lambda^{*}<1$ holds under $\pi n-s_{h} i>0, \lambda^{*}=1$ holds under $\pi n-s_{h} i=0$, and $\lambda^{*}>1$ holds under $\pi n-s_{h} i<0$. A situation in which the steady-state value of the debt-capital ratio is greater than or equal to unity seems to be unrealistic. Thus, it is appropriate to assume that $\pi n-s_{h} i>0$ in the following analysis.

Assumption 1. The following inequality holds:

$$
\pi n-s_{h} i>0 \text {. }
$$

Under this assumption, $\left[s_{f} \pi\left(1-s_{h}\right)+s_{h}\right] n-s_{f} s_{h} i>0$ is also satisfied. Assumption 1 not only ensures that the steady-state value of $\lambda$ is less than unity but also ensures that, as Appendix A1 shows, the self-feedback effect of the debt-capital ratio is negative - that is, $J_{22}=\partial \dot{\lambda} / \partial \lambda<0$. Unless Assumption 1 is satisfied, the self-feedback effect of the

8. It is necessary to assume Harrod-neutral technical progress and a constant potential output capital ratio - that is, a constant capital productivity for the existence of a steady-state equilibrium. 9. Here, we exclude a trivial solution, $\widetilde{k}^{*}=0$. 
debt-capital ratio can be positive - that is, $\partial \dot{\lambda} / \partial \lambda>0$; hence, the economy diverges away from the steady-state equilibrium.

Furthermore, Equation (14) can be rewritten as follows:

$$
n=\frac{s_{f} s_{h} i \lambda^{*}}{\left[s_{f} \pi\left(1-s_{h}\right)+s_{b}\right] \lambda^{*}-s_{b}\left(1-s_{f} \pi\right)}>0 .
$$

Note that $\left[s_{f} \pi\left(1-s_{h}\right)+s_{b}\right] \lambda^{*}-s_{h}\left(1-s_{f} \pi\right)>0$ holds under $\lambda^{*}>0$. This inequality implies that, as Appendix A1 shows, the debt-capital ratio responds negatively to a rise in the rate of capital accumulation - that is, $J_{21}=\partial \dot{\lambda} / \partial g<0$, under $\lambda^{*}>0$.

Finally, by substituting Equations (13) and (14) into Equation (8), we obtain the steady-state value of the capital-effective labor supply ratio as follows:

$$
\widetilde{k}^{*}=\frac{\left[s_{f} \pi\left(1-s_{h}\right)+s_{h}\right] \alpha-\left[s_{f} \pi\left(1-s_{h}-\beta\right)+s_{b}-\gamma\right] g^{*}+s_{f}\left[\gamma\left(1-s_{b}\right)-\beta s_{b}\right] i \lambda^{*}}{\delta\left[g^{*}+s_{f}\left(1-s_{h}\right) i \lambda^{*}\right]} .
$$

The denominator of the right-hand side of Equation (16) is positive, whereas the numerator is ambiguous. If the trend term in the target rate of capital accumulation $\alpha$ is sufficiently large, then the steady-state value of the capital-effective labor supply ratio becomes positive. Thus, we add the following assumption.

Assumption 2. The following inequality holds:

$$
\left[s_{f} \pi\left(1-s_{h}\right)+s_{h}\right] \alpha-\left[s_{f} \pi\left(1-s_{h}-\beta\right)+s_{h}-\gamma\right] g^{*}+s_{f}\left[\gamma\left(1-s_{h}\right)-\beta s_{h}\right] i \lambda^{*}>0 .
$$

\subsection{The financial structure of firms}

Minsky $(1975 ; 1982)$ classified the financial structure of firms into three regimes based on cash-flow accounting: hedge finance, speculative finance, and Ponzi finance. Our next task is to find out which financial regime the steady-state financial structure belongs to. ${ }^{10}$

Table 1 shows the conditions for each financial regime based on the present notation. Hedge finance is a situation with the soundest financial structure; it is defined as the

\section{Table 1 Taxonomy of financial structures of firms}

\begin{tabular}{lcc}
\hline $\begin{array}{l}\text { Finance } \\
\text { regime }\end{array}$ & Definition of each finance regime & $\begin{array}{c}\text { Steady-state } \\
\text { equilibrium }\end{array}$ \\
\hline $\begin{array}{l}\text { Hedge } \\
\text { Speculative }\end{array}$ & $\begin{array}{c}\pi u \geq g+i \lambda+\left(1-s_{f}\right)(\pi u-i \lambda) \\
\pi u<g+i \lambda+\left(1-s_{f}\right)(\pi u-i \lambda) \\
\pi u>i \lambda+\left(1-s_{f}\right)(\pi u-i \lambda) \\
\text { Ponzi }\end{array}$ & Yes \\
\hline
\end{tabular}

10. The earlier studies specifying the taxonomy of the financial structure using Kaleckian models include Charles (2008a: 320-321), Foley (2003: 158-160), Lima/Meirelles (2007: 570-572), Meirelles/Lima (2006: 102-104), and Nishi (2012: 12-14). These earlier studies include only the investment and interest payments in firms' expenditure and do not consider dividends. However, we should not exclude dividends because it is one of the most important expenditure items when considering pro-shareholder income distribution. In addition, Minsky himself explicitly explains that dividend is a component of the firms' expenditure: 'The cash payments made by a unit over a relevant time period equal the spending on current labor and purchased inputs, tax payments, the remittance due to debts that fall due, and dividends' (Minsky 1982: 24). 
situation in which the profits of firms are larger than or equal to their total expenditure that is, the sum of their investment, interest payments, and dividends. By rearranging the conditions for hedge finance, we obtain the following relation:

$$
g-s_{f}(\pi u-i \lambda) \leq 0 .
$$

Speculative finance is defined as a situation in which the profits of firms are less than the sum of their investment, interest payments, and dividends but larger than the sum of their interest payments and dividends. By rearranging the conditions for speculative finance, we obtain the following relations:

$$
g-s_{f}(\pi u-i \lambda)>0 \text { and } \pi u>i \lambda .
$$

Ponzi finance is a situation with the most fragile financial structure; it is defined as a situation in which the profits of firms are less than the sum of their interest payments and dividends. By rearranging the conditions for Ponzi finance, we obtain the following relation:

$$
\pi u \leq i \lambda \text {. }
$$

To which financial regime does the steady-state equilibrium belong?

First, by substituting Equation (4) into Equation (17), we obtain the following inequality:

$$
\left(1-s_{f} \pi\right) g+s_{f} i \lambda \leq 0 .
$$

Equation (20) contradicts the fact that both the capital accumulation rate and debt-capital ratio are positive, implying that the steady-state equilibrium does not become hedge finance. In addition, this means that the former condition of Equation (18) necessarily holds.

Second, by substituting Equation (4) into the latter inequality of Equation (18) and rearranging the resultant expression, we obtain the following relation:

$$
\pi g-s_{h} i \lambda>0 .
$$

If Equation (21) holds, the financial structure of firms becomes speculative; otherwise, the firms are in a Ponzi finance regime. By substituting Equations (13) and (14) into Equation (21), we obtain the following inequality:

$$
\pi n-s_{h} i>0 \text {. }
$$

Equation (22) is the same as Assumption 1. Thus, the financial position of firms in the steady-state equilibrium would necessarily become speculative when the steady-state value of the debt-capital ratio is smaller than unity. Moreover, if $\pi n-s_{h} i<0$ holds (that is, the financial structure is in Ponzi finance), the steady-state value of the debt-capital ratio is larger than unity, and if $\pi n-s_{h} i=0$ holds (that is, the financial structure is in the border between speculative and Ponzi finance regimes), the steady-state value is equal to unity.

\subsection{Stability}

We next consider the local stability of the steady-state equilibrium. To analyse the local stability of the steady-state equilibrium, we linearize Equations (8), (11), and (12) around the equilibrium and investigate the corresponding Jacobian matrix. ${ }^{11}$

11. For details of the stability analysis, see Appendix A1. In Appendix A1, we assume the Keynesian stability condition to hold, which ensures the stability of quantity adjustment of the goods market. However, Skott $(2010 ; 2012)$ and Skott/Zipperer (2012) challenge the validity of the Keynesian stability condition in the long run. 
We introduce the following definition.

Definition 1. If $\left(\gamma-\delta \widetilde{k}^{*}\right)\left(1-s_{h}\right)-\beta s_{h}>0$, the rate of capital accumulation in the steadystate equilibrium is debt-led. On the other hand, if $\left(\gamma-\delta \widetilde{k}^{*}\right)\left(1-s_{h}\right)-\beta s_{h}<0$, the rate of capital accumulation in the steady-state equilibrium is debt-burdened. ${ }^{12,13}$

With this definition, we obtain the following propositions.

Proposition 1. Suppose that, in the steady-state equilibrium, the rate of capital accumulation is debt-led. Then, the steady-state equilibrium is locally stable.

Proposition 2. Suppose that, in the steady-state equilibrium, the rate of capital accumulation is debt-burdened. Then, in the case of $J_{11} J_{22}-J_{12} J_{21}>0$, the steady-state equilibrium is locally stable. On the other hand, in the case of $J_{11} J_{22}-J_{12} J_{21}<0$, the higher adjustment speed of the rate of capital accumulation makes the steady-state equilibrium stable, whereas the lower adjustment speed of the rate of capital accumulation makes the steady-state equilibrium unstable. Moreover, in the case of $J_{11} J_{22}-J_{12} J_{21}<0$, limit cycles occur when the adjustment speed of the rate of capital accumulation lies within some range.

We will now explain why there occur limit cycles under the debt-burdened case. First, when the adjustment speed of the rate of capital accumulation is sufficiently high, the dynamics of the system could become stable because the negative self-feedback mechanism of the rate of capital accumulation becomes strong. Second, under the debt-burdened regime, a rise in the debt-capital ratio decreases the rate of capital accumulation $\left(J_{12}=\partial \dot{g} / \partial \lambda<0\right)$, and the debt-capital ratio is counter-cyclical $\left(J_{21}=\partial \dot{\lambda} / \partial g<0\right)$, which implies that the dynamics of the system could become unstable. Thus, limit cycles occur in the boundary between the stable feedback effect and the unstable feedback effect.

\section{COMPARATIVE STATIC ANALYSIS}

We investigate the effects of changes in the natural rate of growth, retention ratio, profit share, and interest rate on the debt-capital ratio, rate of capacity utilization, capital-effective labor supply ratio, and employment rate. Table 2 shows the results of our comparative static analysis. ${ }^{14}$

Summarizing the above results, we obtain the following propositions. ${ }^{15}$

Proposition 3. A decrease in the retention ratio of firms worsens the financial structure of firms. By contrast, an increase in the profit share, a decrease in the interest rate, and an increase in the natural rate of growth improve the financial structure of firms.

12. In our model, the regime of rate of capital accumulation depends on the level of endogenous variable, $\widetilde{k}$; this differs from earlier studies (Hein 2007; Lavoie 1995; Sasaki/Fujita 2012; Taylor 2004). For example, if the steady-state value of the capital-effective labor supply ratio is sufficiently large, the rate of capital accumulation in the steady state exhibits a debt-burdened regime. On the other hand, if the steady-state value of the capital-effective labor supply ratio is sufficiently small, the rate of capital accumulation in the steady state exhibits a debt-led regime.

13. If we assume both $\gamma=0$ and $\delta=0$, as in Charles (2008a; 2008b), the rate of capital accumulation is always debt-burdened.

14. For details of our comparative static analysis, see Appendix A2.

15. Table 2 shows the effect of an increase in animal spirits $\alpha$ on the steady-state values of the endogenous variables and the effect of a change in each parameter on the steady-state value of the rate of capital accumulation. These results are easily verified by Equations (13), (14), (16), and (A10) in Appendix A2. 
Table 2 Results of comparative static analysis

\begin{tabular}{lccccc}
\hline & $s_{f}$ & $\pi$ & $i$ & $n$ & $\alpha$ \\
\hline$\lambda^{*}$ & - & - & + & - & 0 \\
$u^{*}$ & - & - & + & $?^{\mathrm{a}}$ & 0 \\
$\widetilde{k}^{*}$ & $-/+^{\mathrm{b}}$ & $-/+^{\mathrm{b}}$ & $+/-^{\mathrm{b}}$ & $?^{\mathrm{a}}$ & + \\
$e^{*}$ & $-/ ?^{\mathrm{b}}$ & $-/ ?^{\mathrm{b}}$ & $+/ ?^{\mathrm{b}}$ & $?^{\mathrm{a}}$ & + \\
$g^{*}$ & 0 & 0 & 0 & + & 0 \\
\hline Notes: & \\
a. ?' means the effect is ambiguous in sign. \\
b. A left sign corresponds to the debt-led case, while a right sign corresponds to the \\
debt-burdened case.
\end{tabular}

Proposition 4. A decrease in the retention ratio increases the rate of capacity utilization. By contrast, an increase in the profit share and a decrease in the interest rate decrease the rate of capacity utilization.

Proposition 5. Suppose that, in the steady-state equilibrium, the rate of capital accumulation is debt-led. Then, a decrease in the retention ratio of firms increases both the capital-effective labor supply ratio and the rate of employment. Moreover, an increase in the profit share and a decrease in the interest rate decrease both the capital-effective labor supply ratio and the rate of employment.

Proposition 6. Suppose that, in the steady-state equilibrium, the rate of capital accumulation is debt-burdened. Then, a decrease in the retention ratio of firms decreases the capital-effective labor supply ratio. However, an increase in the profit share and a decrease in the interest rate increase the capital-effective labor supply ratio. Moreover, these effects on the rate of employment can be positive or negative.

\section{CHANGES IN FINANCIAL STRUCTURE THROUGH TRANSITIONAL DYNAMICS}

In Section 3.2, we showed analytically that the financial structure of firms exhibits a speculative finance regime in the steady-state equilibrium. However, a situation exists in which the financial structure diverges from the domain of speculative finance and enters the domain of Ponzi finance through transitional dynamics. In other words, the cash flow $\pi u-i \lambda$ is always positive in the steady-state equilibrium but can become negative through transitional dynamics.

It is unreasonable to expect firms to pay dividends to shareholders when the cash flow is negative. Therefore, in the following numerical simulations, we assume that when the cash flow is strictly positive $(\pi u-i \lambda>0)$, the retention ratio will become strictly less than unity $\left(0<s_{f}<1\right)$ and the firms will pay dividends, and that when the cash flow is negative or equal to zero $(\pi u-i \lambda \leq 0)$, the retention ratio will become unity $\left(s_{f}=1\right)$ and the firms will not pay dividends.

\subsection{Debt-led case}

Let us now consider a case in which the rate of capital accumulation is debt-led in the steady-state equilibrium. In our numerical example, we set the parameters as 

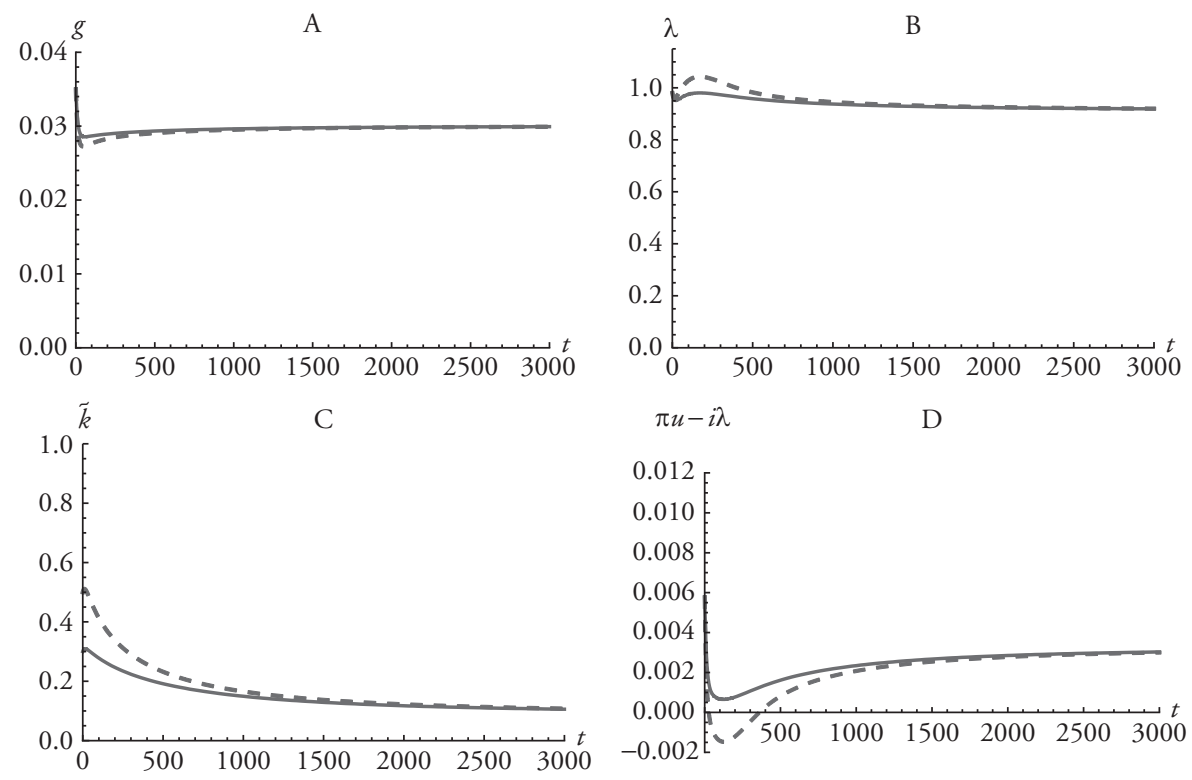

Figure 2 Transitional dynamics in a debt-led case

follows: $n=0.03, s_{f}=0.8, s_{b}=0.2, \pi=0.35, \quad i=0.05, \quad \alpha=0.025, \quad \beta=0.03$, $\gamma=0.04, \delta=0.05$, and $\phi=0.1$. In this setting, we obtain economically meaningful steady-state values such as $g^{*}=0.03, \lambda^{*}=0.915$, and $\widetilde{k}^{*}=0.095$. Moreover, from $\left(\gamma-\delta \tilde{k}^{*}\right)\left(1-s_{h}\right)-\beta s_{h}=0.022>0$, we confirm that the rate of capital accumulation is debt-led in the steady state.

Setting, additionally, the initial conditions to $g(0)=0.035, \lambda(0)=0.98$, and $\widetilde{k}(0)=0.3$, we obtain the transitional dynamics of the endogenous variables, depicted as solid lines in Figure 2. As these solid lines show, all the endogenous variables converge monotonically to their steady-state values. Furthermore, graph D of Figure 2 shows the transition of $\pi u-i \lambda$. As Equation (19) indicates, the sign of $\pi u-i \lambda$ becomes negative when the financial structure of the firms exhibits a Ponzi finance regime. Although $\pi u-i \lambda$ once showed a sharp decline, it does not become negative under the present setting, implying that the financial structure of firms never falls into the Ponzi finance regime.

Now, leaving the parameters unchanged, we raise the initial value of the capital-effective labor supply ratio from $\widetilde{k}(0)=0.3$ to $\widetilde{k}(0)=0.5$. The transitional dynamics of the endogenous variables then change to the dashed lines in Figure 2. Figure 2's graph B shows that when the initial value is given relatively far away from the steady-state value, the debtcapital ratio overshoots and becomes more than unity. Figure 2's graph D shows that the sign of $\pi u-i \lambda$ becomes negative in a certain period and finally converges to the steady state in the positive area. Thus, a relatively small shock in an economy keeps the financial structure of firms in the speculative finance area, whereas a relatively large shock temporally drives the firms into the Ponzi finance regime.

\subsection{Debt-burdened case}

Next, we consider the case in which the capital accumulation rate is debt-burdened in the steady-state equilibrium. Here, we set the parameters as follows: $n=0.015, s_{f}=0.8$, 
$s_{h}=0.1, \pi=0.35, i=0.05, \alpha=0.1, \beta=0.03, \gamma=0.04$, and $\delta=0.05$. We additionally set the initial conditions to $g(0)=0.02, \lambda(0)=0.8$, and $\widetilde{k}(0)=10$. In this example, we obtain economically meaningful steady-state values such as $g^{*}=0.015, \lambda^{*}=0.844$, and $\widetilde{k}^{*}=13.998$. Moreover, we can confirm that the rate of capital accumulation is debtburdened because $\left(\gamma-\delta \widetilde{k}^{*}\right)\left(1-s_{h}\right)-\beta s_{h}=-0.596<0$ holds.

In this setting, if the adjustment speed of the capital accumulation rate is assumed to be $\phi=0.0008$, limit cycles occur, which we have described in Section 3.3. The solid lines in Figure 3 give the transitional dynamics of the rate of capital accumulation, debt-capital ratio, and capital-effective labor supply ratio. Moreover, Figure 3's graph D shows the transitional dynamics of $\pi u-i \lambda$, and its sign repeatedly becomes positive and negative, implying cyclical fluctuations between the speculative finance and Ponzi finance regimes.

The mechanism of the financial structure of firms circulating between speculative finance and Ponzi finance is explained as follows. Suppose that a shock in an economy leads to a reduction in the capital-effective labor ratio. Now, the employment rate would decrease and the firms' incentive to expand production would become strong. Increases in the incentives for investment would raise the rate of capital accumulation and decrease the debt-capital ratio. The financial position would then become speculative finance. However, a rise in the rate of capital accumulation has a positive impact on both the capital-effective labor supply ratio and employment rate. When the employment rate approaches its peak, the rate of capital accumulation begins to pass through its downturn phase. A decrease in the rate of capital accumulation would increase the debt-capital ratio, which in turn drives the financial position to Ponzi finance. In a situation where the debtcapital ratio is sufficiently high, the rate of capital accumulation starts to decrease due to the debt-burdened property, and the economy returns to its initial position.

Note, here, that the cycles in our model are not Minskyan. According to Lavoie (1986-1987), Minskyan models have the following two characteristics: (1) the leverage ratio and the rate of capital accumulation move in the same direction, that is, the leverage
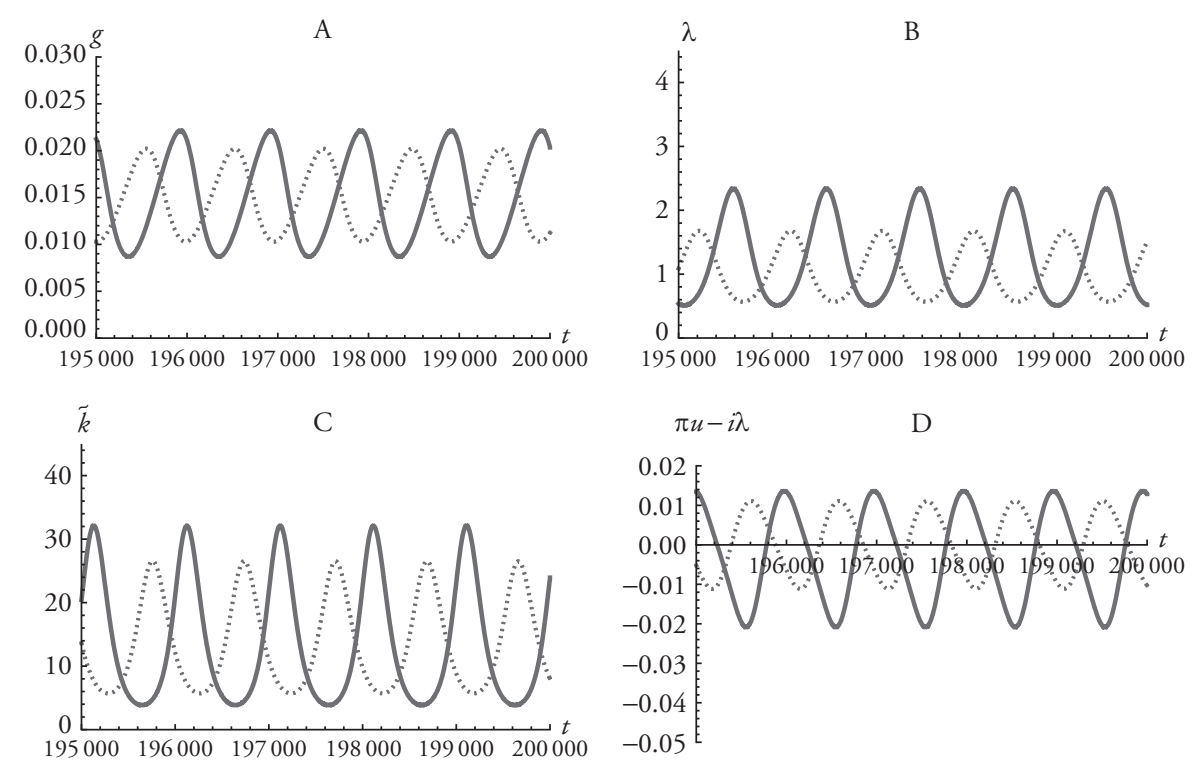

\section{Figure 3 Transitional dynamics in a debt-burdened case}


ratio is pro-cyclical to capital accumulation; and (2) the rate of capital accumulation and the interest rate move in the same direction, that is, in investment booms, the interest rate increases.

With regard to the first characteristic, as Appendix A1 shows, the sign of $J_{21}$ in the Jacobian matrix is negative, which implies that the debt-capital ratio is counter-cyclical to the rate of capital accumulation. ${ }^{16}$ By using data for real GDP growth and the leverage ratio in developed countries, Lavoie/Seccareccia (2001) show that, in reality, the leverage ratio is not pro-cyclical, and, in some cases, it is counter-cyclical. Hence, our model is realistic, though not Minskyan.

With regard to the second characteristic, the interest rate is fixed in our model. Our contribution is that we show the occurrence of cycles even though the interest rate is constant.

The range of fluctuations in business cycles depends on the parameters of the model. If we decrease the retention ratio from $s_{f}=0.8$ to $s_{f}=0.795$, keeping all the other parameters unchanged, the transitional dynamics of endogenous variables would change from the solid lines to the dotted lines in Figure 3: a decline in the retention ratio would diminish the range of the cycle. However, a decrease in the retention ratio increases the steadystate equilibrium value of the debt-capital ratio from $\lambda^{*}=0.844$ to $\lambda^{*}=0.845$, and the firms' financial position deteriorates, though this is not readily seen from Figure 3. Thus, in the debt-burdened regime, a decrease in the retention ratio diminishes the size of business cycles, which is a positive aspect. However, the decrease of the retention ratio raises the equilibrium value of the debt-capital ratio, which is a negative aspect.

\section{CONCLUSIONS}

In this paper, we have presented a post-Keynesian model in which both finance and labor supply constraints influence economic growth. With this model, we have analytically investigated the impacts of pro-shareholders' income distribution on capital/debt accumulation and firms' financial structure. Our results can be summarized as follows.

Stability analysis. If the rate of capital accumulation is debt-led, the steady-state equilibrium is locally stable. On the other hand, if the rate of capital accumulation is debt-burdened, there exist three cases: (1) the steady-state equilibrium is locally stable; (2) the steady-state equilibrium is locally unstable; and (3) limit cycles occur when the adjustment speed of the rate of accumulation lies within some range.

Comparative static analysis. A decrease in the retention ratio makes the financial structure fragile. However, there are three alternative ways to improve the financial structure: increasing profit share, decreasing interest rate, and increasing natural rate of growth. Moreover, a decrease in the retention ratio raises the employment rate in the debt-led case, whereas it does not necessarily do so in the debt-burdened case. Furthermore, an increase in the profit share and a decrease in the interest rate would lead to a decline in the employment rate in the debt-led case. By contrast, they have an ambiguous effect on the employment rate in the debt-burdened case, at least from an analytical point of view.

Transitional dynamics of financial structure. In the steady-state equilibrium, the financial structure of firms becomes speculative finance irrespective of whether the economy exhibits the debt-led or debt-burdened regime. However, a difference exists in the transitional

16. This counter-cyclicality is also obtained in the Minskyan models of Charles (2008b) and Delli Gatti/Gallegati (1990). 
dynamics of the financial position between the debt-led and debt-burdened cases. Our numerical simulations have shown that in the debt-led case, a relatively large shock causes the debt-capital ratio to overshoot, and the financial structure to fall temporally into a Ponzi finance regime; on the other hand, if there occur limit cycles in the debt-burdened case, the financial position circulates between the speculative finance and Ponzi finance regimes. Furthermore, we have clarified that a decrease in the retention ratio diminishes the range of cyclical fluctuations.

Finally, we sum up the total effects of pro-shareholder income distribution on the macroeconomic performance. As we have shown, a decrease in the retention ratio worsens the financial structure of firms and diminishes the range of cyclical fluctuations. By contrast, a rise in the profit share contributes to a sound financial position. Thus, we can conclude that an increase in the profit share is more effective for economic performance than a decline in the retention ratio. However, raising the profit share reduces the rate of capacity utilization, which in turn may lead to a decrease in employment. Therefore, the total assessment of income distribution in favor of shareholders largely depends on which objective - that is, a high employment rate, high growth, stable growth, or healthy financial structure - firms or policymakers would choose.

\section{REFERENCES}

Bhaduri, A., Marglin, S. (1990): Unemployment and the real wage: the economic basis for contesting political ideologies, in: Cambridge Journal of Economics, 14(4), 375-393.

Brav, A., Graham, J.R., Harvey, C.R., Michaely, R. (2005): Payout policy in the 21st century, in: Journal of Financial Economics, 77(3), 483-527.

Cassetti, M. (2003): Bargaining power, effective demand and technical progress: a Kaleckian model of growth, in: Cambridge Journal of Economics, 27(3), 449-464.

Charles, S. (2008a): A post-Keynesian model of accumulation with a Minskyan financial structure, in: Review of Political Economy, 20(3), 319-331.

Charles, S. (2008b): Teaching Minsky's financial instability hypothesis: a manageable suggestion, in: Journal of Post-Keynesian Economics, 31(1), 125-138.

Dallery, T. (2009): Post-Keynesian theories of the firms under financialization, in: Review of Radical Political Economics, 41(4), 492-515.

DeAngelo, H., DeAngelo, L., Skinner, D. (1992): Dividends and losses, in: Journal of Finance, 47(5), 1837-1863.

Delli Gatti, D., Gallegati, M. (1990): Financial instability, income distribution, and the stock market, in: Journal of Post Keynesian Economics, 12(3), 356-374.

Denis, D.J., Osobov, I. (2008): Why do firms pay dividends? International evidence on the determinants of dividend policy, in: Journal of Financial Economics, 89(1), 62-82.

Dutt, A.K. (1992): Conflict inflation, distribution, cyclical accumulation and crisis, in: European Journal of Political Economy, 8(4), 579-597.

Epstein, G.A., Power, D. (2003): Rentier incomes and financial crises: an empirical examination of trends and cycles in some OECD countries, Institute for International Political Economy Working Paper, No. 57.

Fama, E.F., French, K.R. (2001): Disappearing dividends: changing firm characteristics or lower propensity to pay?, in: Journal of Financial Economics, 60(1), 3-43.

Fazzari, S.M., Hubbard, R.G., Peterson, B.C. (1988): Financing constraints and corporate investment, in: Brookings Papers on Economic Activity, 1988(1), 141-206.

Flaschel, P., Skott, P. (2006): Steindlian models of growth and stagnation, in: Metroeconomica, 57(3), 303-338.

Foley, D. (2003): Financial fragility in developing countries, in: Dutt, A.K., Ros, J. (eds), Development Economics and Structuralist Macroeconomics: Essays in Honor of Lance Taylor, Aldershot: Edward Elgar, 157-168. 
Hayashi, F., Inoue, T. (1991): The relation between firm growth and Q with multiple capital goods: theory and evidence from panel data on Japanese firms, in: Econometrica, 59(3), 731-753.

Hein, E. (2006): Interest, debt and capital accumulation: a Kaleckian approach, in: International Review of Applied Economics, 20(3), 337-352.

Hein, E. (2007): Interest rate, debt, distribution, and capital accumulation in a post-Kaleckian model, in: Metroeconomica, 56(2), 310-339.

Hein, E. (2010): Shareholder value orientation, distribution and growth - short- and medium-run effects in a Kaleckian model, in: Metroeconomica, 61(2), 302-332.

Hein, E. (2012): 'Financialization,' distribution, capital accumulation, and productivity growth in a post-Keynesian model, in: Journal of Post-Keynesian Economics, 34(3), 475-496.

Hein, E., van Treeck, T. (2010a): Financialization and rising shareholder power in Kaleckian/postKaleckian models of distribution and growth, in: Review of Political Economy, 22(2), 205-233.

Hein, E., van Treeck, T. (2010b): 'Financialization' in post-Keynesian models of distribution and growth: a systematic view, in: Setterfield, M. (ed.), Handbook of Alternative Theories of Economic Growth, Cheltenham: Edward Elgar, 273-292.

Hoshi, T., Kashyap, A., Scharfstein, D. (1991): Corporate structure, liquidity, and investment: evidence from Japanese industrial groups, in: Quarterly Journal of Economics, 106(1), 33-60.

Kaldor, N. (1966): Marginal productivity and the macroeconomic theories of distribution: comment on Samuelson and Modigliani, in: The Review of Economic Studies, 33(4), 309-319.

Kalecki, M. (1954): Theory of Economic Dynamics, London: George Allen.

Lavoie, M. (1986-1987): Systematic financial fragility: a simplified view, in: Journal of Post Keynesian Economics, 9(2), 258-266.

Lavoie, M. (1995): Interest rate in post-Keynesian models of growth and distribution, in: Metroeconomica, 46(2), 146-177.

Lavoie, M., Seccareccia, M. (2001): Minsky's financial fragility hypothesis: a missing macroeconomic link?, in: Bellofiore, R., Ferri, P. (eds), Financial Fragility and Investment in the Capitalist Economy: The Economic Legacy of Hyman Minsky, Cheltenham: Edward Elgar, 76-96.

Lima, G.T., Meirelles, A.J.A. (2007): Macrodynamics of debt regimes, financial instability and growth, in: Cambridge Journal of Economics, 31(4), 563-580.

Meirelles, A.J.A., Lima, G.T. (2006): Debt, financial fragility, and economic growth: a post Keynesian macromodel, in: Journal of Post Keynesian Economics, 29(1), 93-115.

Minsky, H. (1975): John Maynard Keynes, New York: Columbia University Press.

Minsky, H. (1982): Can 'It' Happen Again?: Essays on Instability and Finance, New York: M.E. Sharpe.

Moore, B.J. (1988): Horizontalists and Verticalists: The Macroeconomics of Credit Money, Cambridge: Cambridge University Press.

Ndikumana, L. (1999): Debt service, financing constraints, and fixed investment: evidence from panel data, in: Journal of Post Keynesian Economics, 21(3), 455-478.

Nishi, H. (2012): A dynamic analysis of debt-led and debt-burdened growth regimes with Minskian financial structure, in: Metroeconomica, 63(4), 634-660.

Onaran, Ö., Stockhammer, S., Grafl, L. (2011): Financialisation, income distribution and aggregate demand in the USA, in: Cambridge Journal of Economics, 35(4), 637-661.

Rochon, L.-P. (1999): Credit, Money, and Production: An Alternative Post-Keynesian Approach, Cheltenham: Edward Elgar.

Ryoo, S., Skott, P. (2008): Financialization in Kaleckian economies with and without labor constraints, in: Intervention: European Journal of Economics and Economic Policies, 5(2), 357-386.

Sasaki, H. (2013): Cyclical growth in a Goodwin-Kalecki-Marx model, in: Journal of Economics, 108(2), 145-171.

Sasaki, H., Fujita, S. (2012): The importance of the retention ratio in a Kaleckian model with debt accumulation, in: Metroeconomica, 63(3), 417-428.

Skott, P. (2010): Growth, instability and cycles: Harrodian and Kaleckian models of accumulation and income distribution, in: Setterfield, M. (ed.), Handbook of Alternative Theories of Economic Growth, Cheltenham: Edward Elgar, 108-131.

Skott, P. (2012): Theoretical and empirical shortcomings of the Kaleckian investment function, in: Metroeconomica, 63(1), 109-138. 
Skott, P., Ryoo, S. (2008): Macroeconomic implication of financialization, in: Cambridge Journal of Economics, 32(6), 827-862.

Skott, P., Zipperer, B. (2012): An empirical evaluation of three post-Keynesian models, in: Intervention: European Journal of Economics and Economic Policies, 9(2), 277-307.

Stockhammer, S. (2004): Financialization and the slowdown of accumulation, in: Cambridge Journal of Economics, 28(5), 719-741.

Taylor, L. (2004): Reconstructing Macroeconomics: Structuralist Proposals and Critiques of the Main Stream, Massachusetts: Harvard University Press.

Van Treeck, T. (2008): Reconsidering the investment-profit nexus in finance-led economies: an ARDL-based approach, in: Metroeconomica, 59(3), 371-404. 


\section{APPENDIX A1 STABILITY ANALYSIS}

The elements of the Jacobian matrix $\mathbf{J}$ that correspond to the system of differential equations (8), (11), and (12) are given as follows:

$$
\begin{aligned}
& J_{11} \equiv \frac{\partial \dot{g}}{\partial g}=-\phi \frac{s_{f} \pi\left(1-s_{h}-\beta\right)+s_{h}-\gamma+\delta \widetilde{k}^{*}}{s_{f} \pi\left(1-s_{h}\right)+s_{h}}<0, J_{12} \equiv \frac{\partial \dot{g}}{\partial \lambda}=\phi \frac{s_{f}\left[\left(\gamma-\delta \widetilde{k}^{*}\right)\left(1-s_{h}\right)-\beta s_{b}\right] i}{s_{f} \pi\left(1-s_{h}\right)+s_{h}}, \\
& J_{13} \equiv \frac{\partial \dot{g}}{\partial \widetilde{k}}=-\phi \delta \frac{g^{*}+s_{f}\left(1-s_{h}\right) i \lambda^{*}}{s_{f} \pi\left(1-s_{h}\right)+s_{h}}<0, J_{21} \equiv \frac{\partial \dot{\lambda}}{\partial g}=\frac{s_{h}\left(1-s_{f} \pi\right)-\left[s_{f} \pi\left(1-s_{h}\right)+s_{h}\right] \lambda^{*}}{s_{f} \pi\left(1-s_{h}\right)+s_{h}}<0, \\
& J_{22} \equiv \frac{\partial \dot{\lambda}}{\partial \lambda}=-\frac{\left[s_{f} \pi\left(1-s_{h}\right)+s_{h}\right] g^{*}-s_{f} s_{h} i}{s_{f} \pi\left(1-s_{h}\right)+s_{h}}<0, J_{23} \equiv \frac{\partial \dot{\lambda}}{\partial \tilde{k}}=0, \quad J_{31} \equiv \frac{\dot{\tilde{k}}}{\partial g}=\widetilde{k}^{*}>0 \\
& J_{32} \equiv \frac{\dot{\widetilde{k}}}{\partial \lambda}=0, J_{33} \equiv \frac{\dot{\tilde{k}}}{\partial \widetilde{k}}=0
\end{aligned}
$$

Note that all the elements are evaluated at the steady-state values.

We suppose that quantity adjustment in the goods market is stable - that is, $J_{11}<0$. The element $J_{12}$ shows the effect of an increase in the debt-capital ratio on the rate of capital accumulation. If its sign is positive, the economy is debt-led in the steady-state equilibrium, and if the sign is negative, the economy is debt-burdened. Finally, $J_{21}<0$ and $J_{22}<0$ are obtained from Assumption 1.

The characteristic equation that corresponds to the Jacobian matrix $\mathbf{J}$ is given as $q^{3}+a_{1} q^{2}+a_{2} q+a_{3}=0$, where $q$ denotes a characteristic root. The coefficients of this equation are given by $a_{1}=-\operatorname{tr} \mathbf{J}=-J_{11}-J_{22}>0, a_{2}=J_{11} J_{22}-J_{12} J_{21}-J_{13} J_{31}$, and $a_{3}=-\operatorname{det} \mathbf{J}=J_{13} J_{22} J_{31}>0$, where trJ denotes the trace of $\mathbf{J}$ and $\operatorname{det} \mathbf{J}$ denotes the determinant of $\mathbf{J}$.

The necessary and sufficient conditions for the local stability of the steady-state equilibrium are given by $a_{1}>0, a_{2}>0, a_{3}>0$, and $a_{1} a_{2}-a_{3}>0$. We clearly obtain $a_{1}>0$ and $a_{3}>0$. However, we do not know the signs of $a_{2}$ and $a_{1} a_{2}-a_{3}$. Thus, we have to investigate whether or not the latter two coefficients are positive.

If the rate of capital accumulation is debt-led, we have $J_{12}>0$, and accordingly, $a_{2}>0$. However, if the rate of capital accumulation is debt-burdened, we have $J_{12}<0$, and hence the sign of $a_{2}$ is ambiguous. We therefore assume the following.

Assumption 3. Even if the rate of capital accumulation is debt-burdened, $a_{2}>0$ holds.

This assumption is satisfied in the situation where the trend term $\alpha$ of the target rate of capital accumulation is sufficiently large.

We next examine the sign of $a_{1} a_{2}-a_{3}$. The coefficients of the characteristic equation can be rewritten as follows:

$$
\begin{gathered}
a_{1}=\Delta_{1} \phi+\Delta_{2}, \quad \Delta_{1} \equiv-\frac{J_{11}}{\phi}>0, \Delta_{2} \equiv-J_{22}>0, \\
a_{2}=\Delta_{3} \phi, \quad \Delta_{3} \equiv \frac{J_{11} J_{22}-J_{12} J_{21}-J_{13} J_{31}}{\phi}>0,
\end{gathered}
$$




$$
\begin{gathered}
a_{3}=\Delta_{4} \phi, \quad \Delta_{4} \equiv \frac{J_{13} J_{22} J_{31}}{\phi}>0, \\
a_{1} a_{2}-a_{3}=f(\phi) \equiv \phi\left(\Delta_{1} \Delta_{3} \phi+\Delta_{2} \Delta_{3}-\Delta_{4}\right) .
\end{gathered}
$$

Note that $\Delta_{1}, \Delta_{2}, \Delta_{3}$, and $\Delta_{4}$ are all positive and independent of $\phi$. From this, $f(\phi)$ shows a parabola with its vertex oriented downward in the $\left(\phi, a_{1} a_{2}-a_{3}\right)$ plane. Furthermore, this quadratic function passes the origin and $\left(\left(\Delta_{4}-\Delta_{2} \Delta_{3}\right) / \Delta_{1} \Delta_{3}, 0\right)$. Now, we can rewrite $\Delta_{4}-\Delta_{2} \Delta_{3}$ as follows:

$$
\Delta_{4}-\Delta_{2} \Delta_{3}=\frac{J_{22}\left(J_{11} J_{22}-J_{12} J_{21}\right)}{\phi} .
$$

If the rate of capital accumulation is debt-led, $\Delta_{4}-\Delta_{2} \Delta_{3}<0$ is obtained because $J_{12}>0$. Then, $f(\phi)>0$ is always satisfied for the range of $\phi>0$. Thus, the steady-state equilibrium is locally stable in the debt-led case because we have $a_{1}>0, a_{2}>0, a_{3}>0$, and $a_{1} a_{2}-a_{3}>0$.

However, if the rate of capital accumulation is debt-burdened, $J_{11} J_{22}-J_{12} J_{21}$ shows an ambiguous sign because $J_{12}<0$. In the case of $J_{11} J_{22}-J_{12} J_{21}>0$, we have $\Delta_{4}-\Delta_{2} \Delta_{3}<0$, and the steady-state equilibrium becomes locally stable, as it is in the debt-led case. By contrast, in the case of $J_{11} J_{22}-J_{12} J_{21}<0$, we have $\Delta_{4}-\Delta_{2} \Delta_{3}>0$. Then, for $\phi \in\left(0,\left(\Delta_{4}-\Delta_{2} \Delta_{3}\right) / \Delta_{1} \Delta_{3}\right)$, we obtain $a_{1}>0, \quad a_{2}>0, \quad a_{3}>0$, and $f(\phi)=a_{1} a_{2}-a_{3}<0$, which implies that the steady-state equilibrium becomes locally unstable. On the other hand, for the range of $\phi>\left(\Delta_{4}-\Delta_{2} \Delta_{3}\right) / \Delta_{1} \Delta_{3}$, we obtain $a_{1}>0, a_{2}>0, a_{3}>0$, and $f(\phi)=a_{1} a_{2}-a_{3}>0$, which implies that the steady-state equilibrium becomes locally stable. Finally, the Hopf bifurcation occurs at $\phi=\left(\Delta_{4}-\Delta_{2} \Delta_{3}\right) / \Delta_{1} \Delta_{3}$ because $a_{1}>0, a_{2}>0, a_{3}>0$, and $f(\phi)=a_{1} a_{2}-a_{3}=0$ are satisfied. This means that there exists a continuous family of non-constant, periodic solutions of the system around $\phi=\left(\Delta_{4}-\Delta_{2} \Delta_{3}\right) / \Delta_{1} \Delta_{3}$.

Summarizing these results, we obtain Propositions 1 and 2 in the text.

\section{APPENDIX A2 COMPARATIVE STATIC ANALYSIS}

\section{A2.1 The debt-capital ratio}

The effects of changes in the retention ratio, profit share, interest rate, and natural rate of growth on the steady-state value of the debt-capital ratio are given as follows:

$$
\begin{aligned}
\frac{d \lambda^{*}}{d s_{f}} & =-\frac{s_{h} n\left(\pi n-s_{h} i\right)}{\left\{\left[s_{f} \pi\left(1-s_{h}\right)+s_{h}\right] n-s_{f} s_{h} i\right\}^{2}}<0, \\
\frac{d \lambda^{*}}{d \pi} & =-\frac{s_{f} s_{h} n\left(n-s_{f} s_{h} i\right)}{\left\{\left[s_{f} \pi\left(1-s_{h}\right)+s_{h}\right] n-s_{f} s_{h} i\right\}^{2}}<0, \\
\frac{d \lambda^{*}}{d i} & =\frac{s_{f} s_{h}^{2} n\left(1-s_{f} \pi\right)}{\left\{\left[s_{f} \pi\left(1-s_{h}\right)+s_{h}\right] n-s_{f} s_{h} i\right\}^{2}}>0, \\
\frac{d \lambda^{*}}{d n} & =-\frac{s_{f} s_{h}^{2} i\left(1-s_{f} \pi\right)}{\left\{\left[s_{f} \pi\left(1-s_{h}\right)+s_{h}\right] n-s_{f} s_{h} i\right\}^{2}}<0 .
\end{aligned}
$$




\section{A2.2 The rate of capacity utilization}

Substituting Equations (13) and (14) into Equation (4), we obtain the steady-state value of the rate of capacity utilization:

$$
u^{*}=\frac{n\left(n-s_{f} s_{h} i\right)}{\left[s_{f} \pi\left(1-s_{h}\right)+s_{h}\right] n-s_{f} s_{h} i} .
$$

From Assumption 1, we have $u^{*}>0$.

The effects of changes in the retention ratio, profit share, interest rate, and natural rate of growth on the steady-state value of the rate of capacity utilization are given as follows:

$$
\begin{gathered}
\frac{d u^{*}}{d s_{f}}=-\frac{n^{2}\left(1-s_{h}\right)\left(\pi n-s_{h} i\right)}{\left\{\left[s_{f} \pi\left(1-s_{h}\right)+s_{h}\right] n-s_{f} s_{h} i\right\}^{2}}<0, \\
\frac{d u^{*}}{d \pi}=-\frac{s_{f} n^{2}\left(1-s_{h}\right)\left(n-s_{f} s_{h} i\right)}{\left\{\left[s_{f} \pi\left(1-s_{h}\right)+s_{h}\right] n-s_{f} s_{h} i\right\}^{2}}<0, \\
\frac{d u^{*}}{d i}=\frac{s_{f} s_{h} n^{2}\left(1-s_{h}\right)\left(1-s_{f} \pi\right)}{\left\{\left[s_{f} \pi\left(1-s_{h}\right)+s_{h}\right] n-s_{f} s_{h} i\right\}^{2}}>0, \\
\frac{d u^{*}}{d n}=\frac{n\left\{\left[s_{f} \pi\left(1-s_{h}\right)+s_{h}\right] n-s_{f} s_{h} i\right\}-s_{f} s_{h} i\left(n-s_{f} s_{h} i\right)}{\left\{\left[s_{f} \pi\left(1-s_{h}\right)+s_{h}\right] n-s_{f} s_{h} i\right\}^{2}} .
\end{gathered}
$$

Only the sign of $d u^{*} / d n$ is ambiguous.

\section{A2.3 The capital-effective labor supply ratio}

We examine the effects of changes in the retention ratio, profit share, interest rate, and natural rate of growth on the capital-effective labor supply ratio.

$$
\begin{aligned}
& \frac{\widetilde{d k}^{*}}{d s_{f}}=\frac{J_{31}\left(A_{2} J_{12}-A_{1} J_{22}\right)}{\operatorname{det} \mathbf{J}}, \\
& \frac{\widetilde{d k}^{*}}{d \pi}=\frac{J_{31}\left(B_{2} J_{12}-B_{1} J_{22}\right)}{\operatorname{det} \mathbf{J}}, \\
& \frac{d \widetilde{d k}^{*}}{d i}=\frac{J_{31}\left(C_{2} J_{12}-C_{1} J_{22}\right)}{\operatorname{det} \mathbf{J}}, \\
& \frac{\widetilde{d k}^{*}}{d n}=\frac{\left(J_{11} J_{22}-J_{12} J_{21}\right) \widetilde{k}^{*}}{\operatorname{det} \mathbf{J}},
\end{aligned}
$$

where

$$
A_{1}=\frac{\phi\left[\left(\gamma-\delta \widetilde{k}^{*}\right)\left(1-s_{h}\right)-\beta s_{b}\right]\left(\pi n-s_{h} i \lambda^{*}\right)}{\left[s_{f} \pi\left(1-s_{h}\right)+s_{b}\right]^{2}}, A_{2}=\frac{s_{h}\left(\pi n-s_{h} i \lambda^{*}\right)}{\left[s_{f} \pi\left(1-s_{h}\right)+s_{h}\right]^{2}}>0
$$




$$
\begin{gathered}
B_{1}=\frac{\phi s_{f}\left[\left(\gamma-\delta \widetilde{k}^{*}\right)\left(1-s_{h}\right)-\beta s_{b}\right]\left[n+s_{f}\left(1-s_{b}\right) i \lambda^{*}\right]}{\left[s_{f} \pi\left(1-s_{h}\right)+s_{h}\right]^{2}}, B_{2}=\frac{s_{f} s_{b}\left[n+s_{f}\left(1-s_{h}\right) i \lambda^{*}\right]}{\left[s_{f} \pi\left(1-s_{b}\right)+s_{h}\right]^{2}}>0, \\
C_{1}=-\frac{\phi s_{f}\left[\left(\gamma-\delta \widetilde{k}^{*}\right)\left(1-s_{h}\right)-\beta s_{h}\right] \lambda^{*}}{s_{f} \pi\left(1-s_{h}\right)+s_{h}}, C_{2}=-\frac{s_{f} s_{h} \lambda^{*}}{s_{f} \pi\left(1-s_{h}\right)+s_{h}}<0 .
\end{gathered}
$$

Note that we have $\operatorname{det} \mathbf{J}<0$. Since Equation (21) holds in the steady state, we obtain $\pi n-s_{h} i \lambda^{*}>0$.

In the debt-led case, we obtain $A_{1}>0, J_{12}>0, A_{2} J_{12}-A_{1} J_{22}>0$, and $\widetilde{d k}^{*} / d s_{f}<0$. In addition, we obtain $B_{1}>0, B_{2} J_{12}-B_{1} J_{22}>0$, and $\widetilde{d k}^{*} / d \pi<0$. Furthermore, we have $C_{1}<0, C_{2} J_{12}-C_{1} J_{22}<0$, and $\widetilde{d k}^{*} / d i>0$. Finally, we obtain $\widetilde{d k}^{*} / d n<0$ because we have $J_{11} J_{22}-J_{12} J_{21}>0$.

In the debt-burdened case, we obtain $A_{1}<0, J_{12}<0, A_{2} J_{12}-A_{1} J_{22}<0$, and $\widetilde{d k}^{*} / d s_{f}>0$. In addition, we obtain $B_{1}<0, B_{2} J_{12}-B_{1} J_{22}<0$, and $\widetilde{d k}^{*} / d \pi>0$. Furthermore, we have $C_{1}>0, C_{2} J_{12}-C_{1} J_{22}>0$, and $\widetilde{d k}^{*} / d i<0$. Finally, the sign of $\widetilde{d k}^{*} / d n$ is ambiguous because the sign of $J_{11} J_{22}-J_{12} J_{21}$ is ambiguous.

\section{A2.4 The employment rate}

The steady-state value of the rate of employment is given by $e=u^{*} \widetilde{k}^{*}$. Accordingly, the effect of an increase in the retention ratio on the rate of employment is decomposed into:

$$
\frac{d e^{*}}{d s_{f}}=\frac{d u^{*}}{d s_{f}} \widetilde{k}^{*}+\frac{d \widetilde{k}^{*}}{d s_{f}} u^{*} .
$$

When the rate of capital accumulation is debt-led, we obtain both $d u^{*} / d s_{f}<0$ and $d \widetilde{k}^{*} / d s_{f}<0$, thereby leading to $d e^{*} / d s_{f}<0$. However, when the rate of capital accumulation is debt-burdened, we obtain $\widetilde{d k}^{*} / d s_{f}>0$, and hence the effect of an increase in the retention ratio on the rate of employment is ambiguous.

From similar deductions, we can examine the effect of changes in other parameters on the rate of employment. 